\title{
Extending the Common Sense Model to Explore the Impact of the Fear of COVID-19 on Quality of Life in an International Inflammatory Bowel Disease Cohort
}

\author{
Bree Hayes $^{1}$. Pragalathan Apputhurai ${ }^{2}$. Antonina Mikocka-Walus ${ }^{3} \cdot$ Manuel Barreiro-de Acosta $^{4}$. \\ Charles N. Bernstein ${ }^{5} \cdot$ Rebecca Burgell $^{6}$. Johan Burisch ${ }^{7}$. Floor Bennebroek Evertsz ${ }^{8} \cdot$ Nuno Ferreira $^{9}$. \\ Lesley A. Graff ${ }^{5}$ Inês A. Trindade ${ }^{10,11} \cdot$ Richard Gearry $^{12} \cdot$ Bobby Lo $^{7}$. Anna Mokrowiecka ${ }^{13} \cdot$ Gabriele Moser $^{14}$. \\ Megan Petrik ${ }^{15} \cdot$ Andreas Stengel $^{16,17} \cdot$ Simon R. Knowles ${ }^{1,6,18,19,20,21}$ (])
}

Accepted: 7 September 2021 / Published online: 24 September 2021

( ) The Author(s), under exclusive licence to Springer Science+Business Media, LLC, part of Springer Nature 2021

\begin{abstract}
The aim of this cross-sectional study was to use an extended common sense model (CSM) to evaluate the impact of fear of COVID-19 on quality of life (QoL) in an international inflammatory bowel disease cohort. An online study involving 319 adults (75\% female, mean (SD) 14.06 (15.57) years of symptoms) completed the Gastrointestinal Symptom Rating Scale, Brief Illness Perceptions Questionnaire, Fear of Contracting COVID-19 Scale, Brief-COPE, Depression, Anxiety and Stress Scale, and the EUROHIS-QOL. The extended CSM had an excellent fit $\left(\chi^{2}(9)=17.06, p=.05, \chi^{2} / N=1.90, \mathrm{RMSEA}=0.05\right.$, $\mathrm{SRMR}=0.04, \mathrm{CFI}=.99, \mathrm{TLI}=.97, \mathrm{GFI}=0.99$ ), indicating the influence of gastrointestinal symptoms on QoL was mediated by illness perceptions, fear of COVID-19, adaptive and maladaptive coping, and psychological distress. Interventions targeting the fear of COVID-19 in the context of an individual's perceptions will likely enhance QoL during the pandemic.
\end{abstract}

Keywords Common sense model · Inflammatory bowel disease $\cdot$ COVID-19 pandemic $\cdot$ Fear $\cdot$ Psychological distress · Quality of life

\section{Introduction}

With 120 million individuals infected and 2.6 million deaths recorded as of the writing of this paper (29 May 2021), the coronavirus (COVID-19) pandemic has had a significant detrimental impact on global society (Worldometer, 2021). The outbreak has been associated with a widespread increase in fears and concerns relating to contagion, uncertainty, quarantine/lockdown, stigmatization, social exclusion, economic consequences, and disruption to routine (e.g., work, education), health care, pharmacy and food supplies (Ahorsu et al., 2020; Bakioğlu et al., 2020; Knipe et al., 2020; Mertens et al., 2020). Moreover, fears relating to contracting COVID19 in the general population have been linked to poorer mental health (Bakioğlu et al., 2020; Lin et al., 2020; Perz et al.,

Simon R. Knowles

sknowles@swin.edu.au

Extended author information available on the last page of the article
2020; Rahman et al., 2020; Satici et al., 2020) and quality of life (QoL; Alyami et al., 2021; Harper et al., 2020).

A systematic review by Mikocka-Walus et al. (2016) found that up to $66 \%$ of individuals living with active inflammatory bowel disease (IBD) reported psychological distress. In a more recent meta analyses, Barberio et al. (2021) also identified high prevalence rates of anxiety (32\%) and depression (25\%) across IBD cohorts. Given that individuals living with IBD are already at risk of experiencing higher levels of psychological distress, and poorer QoL (Knowles et al., 2018), the fear of COVID-19 may exacerbate worse outcomes in this cohort. Research involving IBD cohorts has identified that the COVID-19 pandemic is associated with significant fears about leaving home, and visiting health professionals and/or hospitals for treatment (D'Amico et al., 2020; Grunert et al., 2020; Mosli et al., 2020), and adversely impacts psychological distress (Cheema et al., 2021; Mosli et al., 2020; Trindade \& Ferreira, 2020). To further understand and evaluate the fears relating to COVID-19, Trindade and Ferreira (2020) recently developed a 9-item 5-point Likert-based measure called the Fear of Contracting COVID-19 
Scale. Based on a sample of 124 Portuguese adults living with IBD, the investigators found that higher fears relating to COVID-19 were associated with increased IBD symptoms and psychological distress.

Given the impact of fears relating to COVID-19 in IBD cohorts, exploring the psychosocial processes which may influence patient-reported outcomes (PROs; e.g., psychological distress, QoL) during the COVID-19 pandemic is important. The Common Sense Model (CSM; Leventhal et al., 1980) is a well-established framework purporting that the impact of illness threats (e.g., IBD symptoms) on PROs is mediated by illness perceptions (e.g., beliefs about the cause, consequences) and individual coping styles (e.g., cognitive and behavioural strategies undertaken to manage stress). To date, the CSM has shown applicability across multiple chronic illness conditions (Hagger et al., 2017), including those involving IBD cohorts (Hayes et al., 2020).

Based on the CSM framework, the current study aimed to explore the impact of illness perceptions, fear of COVID-19, and coping styles on the relationships between IBD symptoms and psychological distress, and QoL. It was hypothesized that increased IBD symptoms, illness perceptions, fear of COVID-19, maladaptive coping styles, psychological distress, and decreased adaptive coping styles, would be associated with poorer QoL. Consistent with the CSM, it was also hypothesized that the relationship between IBD symptoms and QoL would be mediated by illness perceptions, fear of COVID-19, adaptive and maladaptive coping styles, and psychological distress.

\section{Methods}

\section{Procedure}

Participants from multiple countries around the world were invited to participate in an online study via patient organizations and social media postings between May and September 2020. The cross-sectional questionnaire was nested within an ongoing, international, prospective study of well-being in individuals living with gastrointestinal conditions (i.e., IBD, irritable bowel syndrome, coeliac disease) during the COVID-19 pandemic (Ferreira et al., 2021).

\section{Inclusion/Exclusion Criteria}

Individuals over the age of 18 years with a diagnosis (selfreported) of IBD by a physician, and an ability to give informed consent and communicate in English were invited to complete a series of validated questionnaires as detailed below. Consent was implied by the participant's decision to complete the questionnaire. The exclusion criterion was an inability to understand written English. Ethical approval to conduct this research was obtained from the University Research Ethics Committee.

\section{Measures}

\section{IBD Symptoms}

The Gastrointestinal Rating Scale (GSRS; Svedlund et al., 1988 ) is a 15 -item questionnaire evaluating commonly reported gastrointestinal symptoms over the past week across five domains: diarrhea, constipation, abdominal pain, reflux, and indigestion. Each item is assessed on a 7-point Likert scale ranging from 1 (no symptoms) to 7 (most pronounced symptoms). The GSRS total is the sum of the 15 items (range 15-105), with higher scores representing higher levels of gastrointestinal symptoms.

\section{Illness Perceptions}

The Brief Illness Perceptions Questionnaire (BIPQ; Broadbent et al., 2006) is an 8-item questionnaire evaluating perceptions of illness across eight dimensions: consequences, timeline, personal control, treatment control, identity, concern, comprehensibility, and emotional response. Each item is assessed on an 11-point Likert scale ranging from 0 (not at all) to 10 (severely affects my life). Based on an exploratory factor analysis using the principal axis factoring method with an Oblimin rotation, and Cronbach's $\alpha$ with item-if-deleted analyses, the BIPQ identified a 4-item factor solution. The four items were composed of: "How much does your illness affect your life", "How much do you experience symptoms from your illness", "How concerned are you about your illness", and "How much does your illness affect you emotionally". The BIPQ score is the average of the four items (range 0-10), with higher scores reflecting poorer illness perceptions. Good internal consistency (.87) was demonstrated for the BIPQ.

\section{Fear of Contracting COVID-19}

The Fear of Contracting COVID-19 Scale (Trindade \& Ferreira, 2020) is a 9-item questionnaire evaluating the fear/ concern of contracting COVID-19. Participants indicate the level of fear/concern they are experiencing regarding situations including "meeting people". Each item is assessed on a 5-point Likert scale ranging from 1 (no fear) to 5 (very much fear) and summed to attain a total (range 9-45), with higher scores indicating greater fear of contracting COVID-19. The Fear of Contracting COVID-19 Scale demonstrated strong internal consistency (.94). 


\section{Coping Styles}

The Brief Coping Operations Preference Enquiry (BriefCOPE; Carver, 1997) is a 28 -item questionnaire evaluating 14 conceptually different coping styles. Each item is measured with a 4-point Likert scale ranging from 1 (not at all) to 4 (a lot). Consistent with recommendations by the scale author (Carver, 1997) and previous research involving IBD cohorts (Knowles et al., 2011, 2013), an exploratory factor analysis was undertaken. Using the principal axis factoring method with an Oblimin rotation and Cronbach's $\alpha$ with item-if-deleted analyses, two coping styles were found, namely maladaptive and adaptive coping styles.

Consistent with the previous research (Carver, 1997; Carver et al., 1989), the subscale descriptions (i.e., maladaptive and adaptive coping styles) were based on their relationship to patient-reported outcomes (PROs; i.e., psychological distress and quality of life). That is, maladaptive coping styles refers to items that had an adverse relationship with the PROs, while the adaptive coping styles subscale consisted of items that had a beneficial relationship with the PROs. Maladaptive coping styles had four items composed of: "I've been saying to myself this isn't real", "I've been giving up trying to deal with it", "I've been refusing to believe that it has happened", and "I've been blaming myself for things that happened", with acceptable internal consistency (.70). Adaptive coping styles had six items composed of: "I've been concentrating my efforts on doing something about the situation I'm in", "I've been getting emotional support from others", "I've been getting help and advice from other people", "I've been getting comfort and understanding from someone", "I've been doing something to think about it less, such as going to movies, watching TV, reading, daydreaming, sleeping, or shopping", and "I've been trying to get advice or help from other people about what to do", with good internal consistency (.83). Each of the subscale scores are obtained by averaging the items (range $1-4$ ), with higher scores indicating a greater engagement in maladaptive or adaptive coping styles.

\section{Psychological Distress}

The Depression, Anxiety and Stress Scale (Lovibond \& Lovibond, 1995) is a 21-item questionnaire with seven items from three subscales evaluating depression, anxiety, and stress. Participants reflect on experiences and feelings and indicate how much each of the 21 statements applied to them over the past week. For example, "I found it hard to wind down" is assessed on a 4-point Likert scale ranging from 0 (did not apply to me at all) to 3 (applied to me very much, or most of the time). A total measure of psychological distress is calculated by summing all 21 items and multiplying by two (range $0-126$ ), with higher scores reflecting higher levels of distress. The DASS-21 demonstrated strong internal consistency (.95). The three subscales of the DASS21 are derived by summing items, then multiplying by 2 to calculate the subscale score (range 0-42). Each subscale demonstrated strong internal consistency (depression .93, anxiety .86, stress .92). Severity labels for the subscales scores were applied according to the cut-off scores recommended by Lovibond and Lovibond (1995).

\section{Quality of Life}

The EUROHIS-QOL (Schmidt et al., 2006) is an 8-item index evaluating general well-being in the context of goals, expectations, concerns, and societal systems. Participants address eight questions and indicate how they feel about their QoL over the past two weeks. For example, "How satisfied are you with your health?" is assessed on a 5-point Likert scale ranging from 1 (very dissatisfied) to 5 (very satisfied). The EUROHIS-QoL total is the sum of the eight items (range 8-40), with higher scores representing higher QoL. Good internal consistency (.85) was demonstrated for the EUROHIS-QOL.

\section{Statistical Analyses}

All analyses were performed with SPSS v27 and AMOS v27. Data were screened and assumptions tested preceding analyses. Correlational analysis was conducted to test the first hypothesis, while a structural equation model (SEM) was developed to evaluate the second (see research protocol, Ferreira et al., 2021). Prior to the SEM being derived, the correlations were utilized with a multivariate analysis of variance (MANOVA) to evaluate the impact of participant demographics (e.g., age, gender, education level) on study variables. To ensure the convergent and divergent validity of the study variables (Fornell \& Larcker, 1981), a measurement model was also tested prior to a SEM being developed. Based on inspection of standardized residuals, modification indices, and guided by past research, the final model was derived by an iterative process of adding pathways and removing variables until the criteria recommended by $\mathrm{Hu}$ and Bentler (1999) was met $\left(\chi^{2} p>.05 ; \chi^{2} / N=1-3\right.$, RMSEA $<.07$, SRMR $<.10$, CFI $>.95$, GFI $>.95$ ).

\section{Results}

Three hundred and nineteen adults with IBD from multiple countries around the world with a mean age of 40.37 years $(\mathrm{SD}=15.57$ years) participated. The mean duration of IBD symptoms was 14.06 (range 0-50) years. Of the 319 participants, 137 (43\%) were engaging in strict to moderate social isolation (i.e., not going out at all or only for food), and four 
(1\%) had been infected with COVID-19. Regarding levels of psychological distress, $11 \%$ and $12 \%$ reported severe/ extremely severe anxiety and depression symptoms, respectively. See Table 1 for additional participant characteristics.

Table 2 shows the descriptive and correlational analyses of the study variables. The results supported the first hypothesis that increased IBD symptoms, illness perceptions, fear of COVID-19, maladaptive coping styles, and psychological distress, and decreased adaptive coping styles, were associated with poorer QoL.

Prior to the SEM being derived, correlational analysis and a MANOVA indicated that demographic factors 'country' and 'living with' (see Table 1) significantly influenced the study variables. As insufficient data were obtained to enable country comparisons (e.g., $n=1$ for France, Switzerland, Northern Ireland, $n=2$ for Ireland, Portugal, Scotland, Sweden, Romania), and similar results were found when controlling for 'living with', these factors were not included in further model development. All latent variables were retained in the final model which had an excellent fit $\left(\chi^{2}(9)=17.06, p=.05\right.$, RMSEA $=0.05$, SRMR $=0.04$, $\mathrm{CFI}=0.99$, TLI $=0.97$, GFI $=0.99$; see Fig. 1 ). The total amount of variance accounted for in each of the variables was $32 \%$ of illness perceptions, $17 \%$ of fear of COVID-19, $4 \%$ of adaptive coping styles, $9 \%$ of maladaptive coping styles, $41 \%$ of psychological distress, and $46 \%$ of QoL.

The results also supported the second hypothesis that several mediated pathways were identified as expected. Illness perceptions fully mediated the relationships between IBD symptoms and adaptive coping styles, and maladaptive coping styles, and fear of COVID-19, and psychological distress, and QoL. Further, the relationship between illness perceptions and QoL was partially mediated by adaptive coping styles, and maladaptive coping styles, and fear of COVID-19, and psychological distress. Finally, the relationships between maladaptive coping styles and QoL, and fear of COVID-19 and QoL, were partially and fully mediated by psychological distress. There was also a positive association between adaptive and maladaptive coping styles $(p<.001)$.

\section{Discussion}

The aim of the current study was to utilize an extended CSM to explore the impact of illness perceptions, fear of COVID-19, and coping styles on the relationships between IBD symptoms and psychological distress, and QoL. Consistent with previous research, the results supported the first hypothesis that poorer QoL was associated with increased IBD symptoms (Knowles et al., 2018; Mikocka-Walus et al., 2016), poorer illness perceptions (Dorrian et al., 2009; van der Have et al., 2013, 2015; van Erp et al., 2017; Zhang et al., 2016), escalating fear of COVID-19 (Alyami et al.,
2021; Harper et al., 2020), increased maladaptive coping styles, and psychological distress (Hayes et al., 2020), and reduced adaptive coping styles (McCombie et al., 2013, 2015; Zhang et al., 2016).

We also found that illness perceptions, adaptive coping styles, maladaptive coping styles, and psychological distress mediated the relationship between IBD symptoms and QoL. These findings are consistent with previous IBD research (see review; Hayes et al., 2020), which emphasizes the significant adverse impact of illness perceptions, maladaptive coping styles, and psychological distress, and the beneficial influence of adaptive coping styles, on the relationships between IBD symptoms and psychological distress, and/or QoL.

As identified in previous research, the COVID-19 pandemic has had a pervasive detrimental impact on the wellbeing of individuals living with IBD (Cheema et al., 2021; Mosli et al., 2020; Trindade \& Ferreira, 2020). Extending past research and supporting the second hypothesis was the finding that illness perceptions predicted COVID-19 fears, and that these fears in turn exacerbated psychological distress. These novel findings provide further evidence that the current pandemic and fears relating to it can and do promote psychological distress (Trindade \& Ferreira, 2020) and poorer QoL (Hayes et al., 2020). With many individuals living in isolation (41\% of participants in the current study), fears about COVID-19 relate not only to being at a greater risk of being infected by the coronavirus (Bodini et al., 2020; D'Amico et al., 2020; Grunert et al., 2020; Mosli et al., 2020; Zingone et al., 2020), but also to having reduced access to medical and allied health support, medications, and information about the impact of COVID-19 on IBD (Cheema et al., 2021; D'Amico et al., 2020; Mosli et al., 2020). Given the current and likely ongoing psychosocial challenges associated with the pandemic (e.g., posttraumatic symptoms; Mukhtar, 2020), and the bi-directional nature of the processes involved, addressing illness perceptions, the fear of COVID-19, and psychological distress is essential to enhancing QoL in IBD cohorts.

The findings from this study are relevant to clinical practice. Based on the SEM, the research suggests that psychological interventions targeting illness perceptions, fear of COVID-19, and coping styles will likely improve management of IBD and PROs (e.g., psychological distress and QoL). The findings further suggest that clinicians should ask about and attend to patients' fears regarding not only their illness, but also those relating to COVID-19. For example, screening for these could occur during IBD appointments and followed up with referrals to psychogastroenterology providers. Psychological interventions such as Cognitive Behaviour Therapy (Beck, 2011), are also likely to improve QoL by addressing fears relating to COVID-19, and targeting maladaptive illness perceptions and coping strategies. In 
Table 1 Participant characteristics

\begin{tabular}{|c|c|c|}
\hline Characteristics & $n$ & $\%$ \\
\hline \multicolumn{3}{|l|}{ Gender } \\
\hline Female & 78 & 24.5 \\
\hline Male & 240 & 75.2 \\
\hline Non-specific & 1 & 0.3 \\
\hline \multicolumn{3}{|l|}{ Country (current) } \\
\hline Poland & 61 & 19.1 \\
\hline Australia & 52 & 16.3 \\
\hline New Zealand & 52 & 16.3 \\
\hline England & 33 & 10.3 \\
\hline Netherlands & 31 & 9.7 \\
\hline Denmark & 30 & 9.4 \\
\hline Canada & 22 & 6.9 \\
\hline United States of America & 14 & 4.4 \\
\hline Other* & 24 & 7.6 \\
\hline \multicolumn{3}{|l|}{ Highest education } \\
\hline Primary school & 21 & 6.6 \\
\hline Secondary school & 38 & 11.9 \\
\hline Certificate/trade & 52 & 16.3 \\
\hline Undergraduate degree & 129 & 40.5 \\
\hline Postgraduate degree & 79 & 24.7 \\
\hline \multicolumn{3}{|l|}{ Relationship status } \\
\hline Married & 153 & 48 \\
\hline Single & 116 & 36 \\
\hline De facto & 29 & 9 \\
\hline Other (separated, widowed, divorced) & 21 & 7 \\
\hline \multicolumn{3}{|l|}{ Dependents } \\
\hline None & 112 & 35.1 \\
\hline One & 39 & 12.2 \\
\hline Two & 50 & 15.7 \\
\hline Three or more & 27 & 8.4 \\
\hline Not reported & 91 & 28.6 \\
\hline \multicolumn{3}{|l|}{ Living with } \\
\hline Alone & 51 & 16 \\
\hline Partner & 187 & 58.6 \\
\hline Parent/s & 32 & 10 \\
\hline Friend/s & 6 & 1.9 \\
\hline Other (e.g., other family) & 43 & 13.5 \\
\hline \multicolumn{3}{|l|}{ Living setting } \\
\hline Metropolitan & 124 & 38.9 \\
\hline Regional & 128 & 40.1 \\
\hline Rural & 67 & 21 \\
\hline \multicolumn{3}{|l|}{ Employment status } \\
\hline Full-time & 125 & 39.2 \\
\hline Part-time & 41 & 12.9 \\
\hline Casual & 7 & 2.2 \\
\hline Self-employed & 19 & 6 \\
\hline Unemployed & 28 & 8.8 \\
\hline Retired & 30 & 9.4 \\
\hline Pensioner & 14 & 4.4 \\
\hline Home duties & 15 & 4.7 \\
\hline Student & 20 & 6.3 \\
\hline
\end{tabular}


Table 1 (continued)

\begin{tabular}{|c|c|c|}
\hline Characteristics & $n$ & $\%$ \\
\hline Other (e.g., volunteering) & 20 & 6.3 \\
\hline \multicolumn{3}{|l|}{ Medications } \\
\hline None & 102 & 32 \\
\hline Aminosalicylates & 52 & 16.3 \\
\hline Immunomodulators & 57 & 17.9 \\
\hline Corticosteroids & 22 & 6.9 \\
\hline Biologics & 64 & 20.1 \\
\hline Other (e.g., antibiotics) & 22 & 6.8 \\
\hline \multicolumn{3}{|l|}{ Anxiety (DASS-21 subscale category) } \\
\hline Normal & 214 & 67.1 \\
\hline Mild & 13 & 4.1 \\
\hline Moderate & 56 & 17.6 \\
\hline Severe & 14 & 4.4 \\
\hline Extremely severe & 22 & 6.9 \\
\hline \multicolumn{3}{|l|}{ Depression (DASS-21 subscale category) } \\
\hline Normal & 200 & 62.7 \\
\hline Mild & 43 & 13.5 \\
\hline Moderate & 37 & 11.6 \\
\hline Severe & 10 & 3.1 \\
\hline Extremely severe & 29 & 9.1 \\
\hline \multicolumn{3}{|l|}{ Stress (DASS-21 subscale category) } \\
\hline Normal & 221 & 69.3 \\
\hline Mild & 31 & 9.7 \\
\hline Moderate & 36 & 11.3 \\
\hline Severe & 20 & 6.3 \\
\hline Extremely severe & 11 & 3.4 \\
\hline \multicolumn{3}{|l|}{ Covid-19 situation } \\
\hline Total isolation (have symptoms) & 1 & 0.3 \\
\hline Strict isolation (mandatory quarantine) & 4 & 1.3 \\
\hline Strict isolation (staying at home) & 30 & 9.4 \\
\hline Moderate social isolation (staying at home and only going out for food) & 102 & 32 \\
\hline $\begin{array}{l}\text { Limited social isolation (mostly staying at home, going out for food and seeing } \\
\text { friends/family) }\end{array}$ & 141 & 44.2 \\
\hline No social isolation & 41 & 12.9 \\
\hline \multicolumn{3}{|l|}{ Length of isolation due to COVID-19 (weeks) } \\
\hline $0-4$ & 20 & 6.4 \\
\hline $5-8$ & 31 & 9.7 \\
\hline $9-12$ & 40 & 12.6 \\
\hline $13-16$ & 31 & 9.7 \\
\hline $17-20$ & 9 & 2.7 \\
\hline $21-24$ & 5 & 1.5 \\
\hline $25+$ & 5 & 1.5 \\
\hline Not reported & 178 & 55.8 \\
\hline \multicolumn{3}{|l|}{ Have you been infected with COVID-19? } \\
\hline Yes & 4 & 1.3 \\
\hline No & 315 & 98.7 \\
\hline \multicolumn{3}{|l|}{ Have you been hospitalized due to COVID-19? } \\
\hline Yes & 4 & 1.3 \\
\hline No & 315 & 98.7 \\
\hline
\end{tabular}

*France $0.3 \%$, Germany $0.9 \%$, Ireland $0.6 \%$, Portugal $0.6 \%$, Romania $0.6 \%$, Scotland $0.6 \%$, Sweden $0.9 \%$, Switzerland $0.3 \%$, Spain $1.3 \%$, Northern Ireland $0.3 \%$, Other not specified $1.2 \%$ 


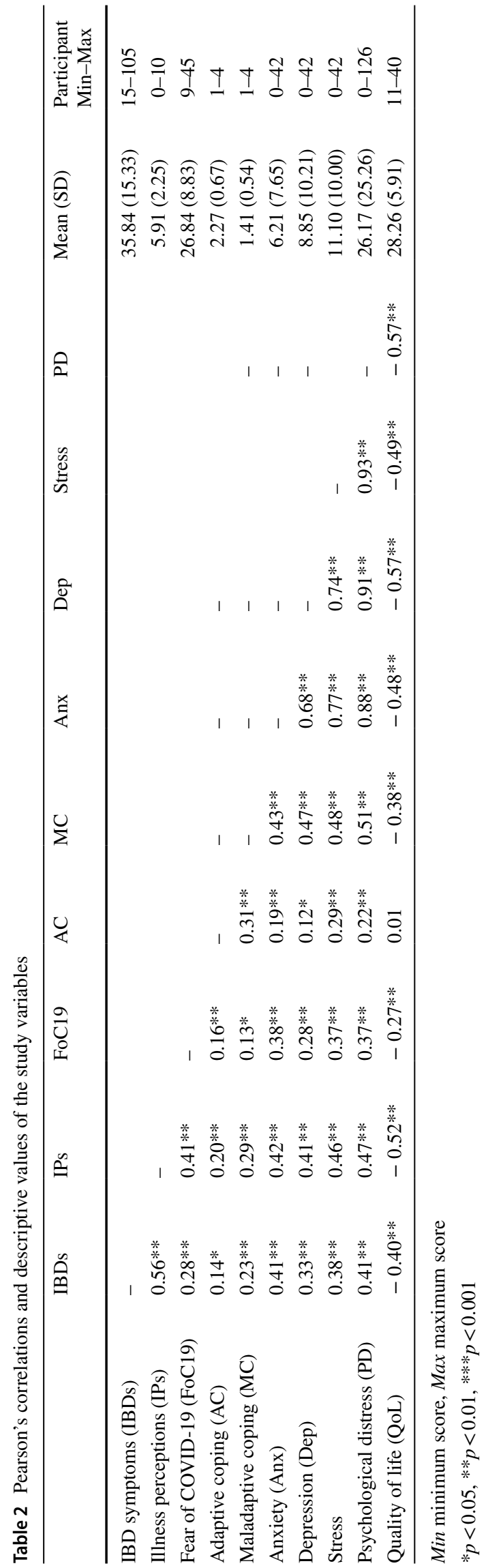

addition, the provision of psychoeducation should address not only disease management, but also patient fears and misperceptions relating to COVID-19, including the recent recommendations by professional bodies to promote COVID-19 vaccination in IBD cohorts (British Society of Gastroenterology, 2021; Gastroenterological Society of Australia, 2021).

Whilst the study is highly topical and novel, it is not without limitations. The current study was limited to English speakers with internet access, potentially under-sampling populations at country and socio-economic levels. It was undertaken in country-specific contexts (e.g., in different phases of the pandemic, lockdown), and relied upon a generic measure of gastrointestinal symptoms and participants' self-reported diagnosis of IBD. Due to the small sample, comparisons across countries were not possible. Finally, the cross-sectional design prevented true causal bi-directional relationships from being established (including how the relationships will also influence IBD symptom severity), and exploration of factors associated with the brain-gut-axis, such as perceived stress (Sexton et al., 2017) and visceral sensitivity (Hayes et al., in press).

Given the pervasive and continuing impact of the COVID-19 pandemic, future research should explore not only the generic fears relating to COVID-19, as conducted in this study, but also IBD-specific COVID-19-related fears. These may include the perceived increased susceptibility to COVID-19 (D'Amico et al., 2020; Mosli et al., 2020) and impact on disease course (D'Amico et al., 2020; Grunert et al., 2020), and beliefs and intentions relating to attaining the COVID-19 vaccine (Dalal et al., 2021). Future research should also seek to explore the potential impact of the pandemic, including IBD-specific COVID-19 fears on disease management, and complications relating to accessing health care teams and medications (Cheema et al., 2021; Mosli et al., 2020). Consistent with previous research applying the CSM in IBD cohorts (Hayes et al., 2020), the current research suggests that illness perceptions, coping styles, and their interactions, influence PROs. Given this, an important focus of future research should be to utilize and extend the CSM framework by adding modifiable factors known to influence disease management and enhance PROs. Future studies should evaluate self-efficacy (Graff et al., 2016), resilience (Sehgal et al., 2020), and psychological flexibility (Kiebles et al., 2010), to better understand adjustment to IBD over time, including during and post the pandemic.

\section{Conclusion}

The coronavirus pandemic has had a pervasive adverse impact on individuals living with IBD. The study demonstrated that the well-being of individuals living with 


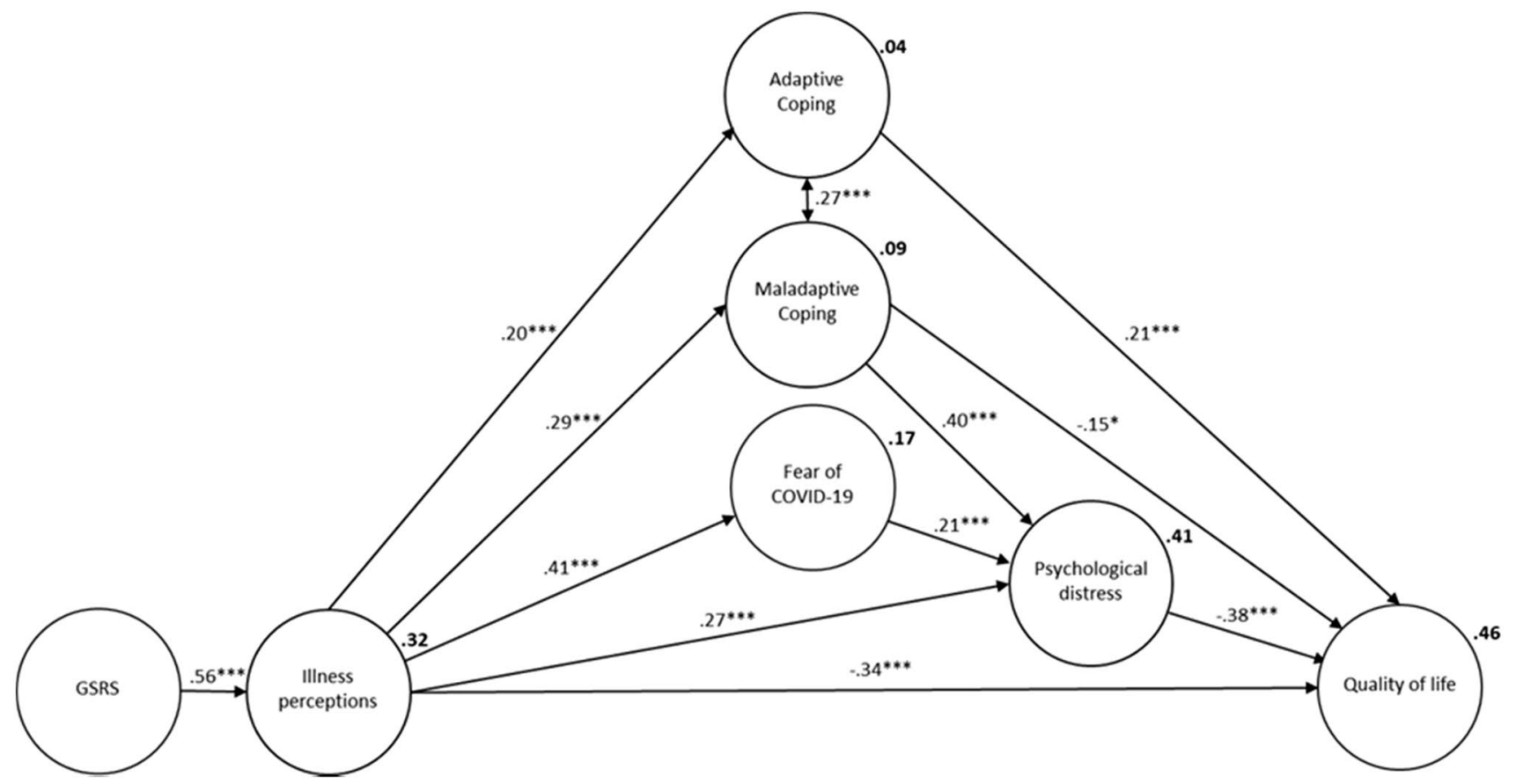

Fig. 1 Final extended CSM (study variables presented with error terms removed; * $p<0.05$, ${ }^{* * *} p<0.001$ )

IBD is significantly negatively impacted by illness perceptions, fear of COVID-19 and maladaptive coping styles, and positively impacted by adaptive coping styles. These results indicate that in addition to addressing coping styles, psychological interventions should focus primarily on providing targeted support to attenuate fears regarding COVID-19 in the context of individuals' perceptions of their IBD. This will likely attenuate psychological distress and enhance QoL in IBD cohorts during the pandemic.

Acknowledgements The authors would like to thank all the participants for the support and interest in our research and Mr Stephan Moller for his assistance in setting up the study questionnaire and supporting recruitment efforts.

Author Contributions All authors contributed to the study conception and design. Material preparation, data collection and analysis were performed by Pragalathan Apputhurai, Simon Knowles and Bree Hayes. The first draft of the manuscript was written by Bree Hayes and all authors commented on previous versions of the manuscript. All authors read and approved the final manuscript.

Funding This work by Mrs Bree Hayes was supported through an Australian Government Research Training Program Scholarship.

Data Availability The data that support the findings of this study are available on request from the senior author, Simon Knowles. The data are not publicly available due to restrictions.

Code Availability Not applicable.

\section{Declarations}

Conflict of interest The authors have no conflicts of interests to declare that are relevant to the content of this article. Outside the present work, A. Mikocka-Walus has served as an invited speaker at IBD-related conferences co-organized by Crohn's \& Colitis Australia (a charity), Janssen and Ferring and received a speaker's fee. Outside the present work, M. Barreiro-de Acosta has served as a speaker, consultant and advisory member for or has received research funding from MSD, AbbVie, Janssen, Kern Pharma, Celltrion, Takeda, Gillead, Celgene, Pfizer, Ferring, Faes Farma, Shire Pharmaceuticals, Dr. Falk Pharma, Chiesi, Gebro Pharma, Adacyte and Vifor Pharma. Outside the present work, C. Bernstein has served on advisory Boards for AbbVie Canada, Amgen Canada, Bristol Myers Squibb Canada, Roche Canada, Janssen Canada, Sandoz Canada, Takeda Canada and Pfizer Canada; consulted for Mylan Pharmaceuticals and Takeda; received educational grants from Abbvie Canada, Pfizer Canada, Takeda Canada and Janssen Canada; been on a speaker's panel for Abbvie Canada, Janssen Canada, Medtronic Canada and Takeda Canada; and, received research funding from Abbvie Canada and Pfizer Canada. Outside the present work, R. Burgell has received speaker's fees for Bayer and is an advisory board member for Atmo and Antara life sciences. Outside the present work, L. A. Graff has been a consultant for Roche Canada. Outside the present work, I. A. Trindade has received consultancy fees from Pfizer Inc. Outside the present work, R. Gearry has served on advisory boards for AbbVie New Zealand and Australia, Zespri New Zealand and Jannsen New Zealand and has received research funding from AbbVie and Zespri. Outside the present work, G. Moser has served as an invited speaker at IBD-related conferences co-organized by Crohn's \& Colitis Self Help group and ÖMCCV Austria and received a speaker's fee from Merck, Gebro Pharma, Dr. Falk Pharma, Abbvie and Bayer. Outside the present work, A. Stengel has served as a consultant for A \& R Berlin, Boehringer-Ingelheim, Takeda, Medice, Microbiotica 
and Schwabe. Outside the present work, M. van Tilburg has been a consultant for Mahana Therapeutics Inc. Outside the present work, S. R. Knowles has served as an invited speaker at IBD-related conferences co-organized by Crohn's \& Colitis Australia (a charity), Janssen, and Ferring and received a speaker's fee and is a member of Medical Advisory Committee for Glutagen Pty Ltd.

Ethical Approval All procedures performed in studies involving human participants were in accordance with the ethical standards of the institutional and/or national research committee and with the 1964 Helsinki Declaration and its later amendments or comparable ethical standards. The study was approved by the Swinburne University of Technology Human Research Ethics Committee on 25th May 2020 (Ref: 202029784430) as well as the local Human Research Ethics Committees of the participating collaborators, as required.

Consent to Participate Informed consent was obtained from all individual participants included in the study.

Consent for Publication Not applicable.

\section{References}

Ahorsu, D. K., Lin, C. Y., Imani, V., Saffari, M., Griffiths, M. D., \& Pakpour, A. H. (2020). The fear of COVID-19 scale: Development and initial validation. International Journal of Mental Health and Addiction. https://doi.org/10.1007/s11469-020-00270-8

Alyami, M., de Albuquerque, J. V., Krägeloh, C. U., Alyami, H., \& Henning, M. A. (2021). Effects of fear of COVID-19 on mental well-being and quality of life among Saudi adults: A path analysis. Saudi Journal of Medicine \& Medical Sciences, 9(1), 24. https:// doi.org/10.4103/sjmms.sjmms_630_20

Bakioğlu, F., Korkmaz, O., \& Ercan, H. (2020). Fear of COVID-19 and positivity: Mediating role of intolerance of uncertainty, depression, anxiety, and stress. International Journal of Mental Health and Addiction. https://doi.org/10.1007/s11469-020-00331-y

Barberio, B., Zamani, M., Black, C. J., Savarino, E. V., \& Ford, A. C. (2021). Prevalence of symptoms of anxiety and depression in patients with inflammatory bowel disease: A systematic review and meta-analysis. The Lancet Gastroenterology \& Hepatology. https://doi.org/10.1016/S2468-1253(21)00014-5

Beck, J. S. (2011). Cognitive behavior therapy: Basics and beyond (2nd ed.). Guilford Press.

Bodini, G., Demarzo, M. G., Casagrande, E., De Maria, C., Kayali, S., Ziola, S., \& Giannini, E. G. (2020). Concerns related to COVID19 pandemic among patients with inflammatory bowel disease and its influence on patient management. European Journal of Clinical Investigation, 50(5), e13233. https://doi.org/10.1111/ eci. 13233

British Society of Gastroenterology. (2021). Inflammatory bowel disease section and IBD Clinical Research Group position statement on SARS-CoV2 vaccination. Retrieved 15 March, 2021, from https://www.bsg.org.uk/covid-19-advice/british-society-of-gastr oenterology-inflammatory-bowel-disease-section-and-ibd-clini cal-research-group-position-statement-on-sars-cov2-vaccination/

Broadbent, E., Petrie, K. J., Main, J., \& Weinman, J. (2006). The brief illness perception questionnaire. Journal of Psychosomatic Research, 60(6), 631-637. https://doi.org/10.1016/j.jpsychores. 2005.10.020

Carver, C. S. (1997). You want to measure coping but your protocol's too long: Consider the brief cope. International Journal of Behavioral Medicine, 4(1), 92. https://doi.org/10.1207/s1532 7558ijbm0401_6
Carver, C. S., Scheier, M. F., \& Weintraub, J. K. (1989). Assessing coping strategies: A theoretically based approach. Journal of Personality and Social Psychology, 56(2), 267. https://doi.org/ 10.1037/0022-3514.56.2.267

Cheema, M., Mitrev, N., Hall, L., Tiongson, M., Ahlenstiel, G., \& Kariyawasam, V. (2021). Depression, anxiety and stress among patients with inflammatory bowel disease during the COVID-19 pandemic: Australian national survey. BMJ Open Gastroenterology, 8(1), e000581. https://doi.org/10.1136/bmjgast-2020-000581

Dalal, R. S., McClure, E., Marcus, J., Winter, R. W., Hamilton, M. J., \& Allegretti, J. R. (2021). COVID-19 vaccination intent and perceptions among patients with inflammatory bowel diseases. Clinical Gastroenterology and Hepatology. https://doi.org/10. 1016/j.cgh.2021.02.004

D’Amico, F., Rahier, J. F., Leone, S., Peyrin-Biroulet, L., \& Danese, S. (2020). Views of patients with inflammatory bowel disease on the COVID-19 pandemic: A global survey. The Lancet Gastroenterology \& Hepatology, 5(7), 631-632. https://doi.org/10.1016/ S2468-1253(20)30151-5

Dorrian, A., Dempster, M., \& Adair, P. (2009). Adjustment to inflammatory bowel disease: The relative influence of illness perceptions and coping. Inflammatory Bowel Diseases, 15(1), 47-55. https:// doi.org/10.1002/ibd.20583

Ferreira, N., Mikocka-Walus, A., van Tilburg, M. A. L., Graff, L. A., Apputhurai, P., Barreiro-de Acosta, M., et al. (2021). The Impact of the coronavirus (COVID-19) pandemic on individuals with gastrointestinal disorders: A protocol of an international collaborative study. Journal of Psychosomatic Research 148:110561

Fornell, C., \& Larcker, D. F. (1981). Structural equation models with unobservable variables and measurement error: Algebra and statistics. Sage Publications.

Gastroenterological Society of Australia. (2021). COVID-19 Vaccination in Patients with Gastrointestinal and Liver Disorders. Retrieved 15 March, 2021, from https://www.gesa.org.au/educa tion/covid-19/

Graff, L. A., Sexton, K. A., Walker, J. R., Clara, I., Targownik, L. E., \& Bernstein, C. N. (2016). Validating a measure of patient self-efficacy in disease self-management using a population-based IBD cohort: The IBD self-efficacy scale. Inflammatory Bowel Diseases, 22(9), 2165-2172. https://doi.org/10.1097/MIB.00000 00000000856

Grunert, P. C., Reuken, P. A., Stallhofer, J., Teich, N., \& Stallmach, A. (2020). Inflammatory bowel disease in the COVID-19 pandemic: The patients' perspective. Journal of Crohn's and Colitis, 14(12), 1702-1708. https://doi.org/10.1093/ecco-jcc/jjaa126

Hagger, M., Koch, S., Chatzisarantis, N., \& Orbell, S. (2017). The common sense model of self-regulation: Meta-analysis and test of a process model. Psychological Bulletin, 143(11), 1117. https:// doi.org/10.1037/bul0000118

Harper, C. A., Satchell, L. P., Fido, D., \& Latzman, R. D. (2020). Functional fear predicts public health compliance in the COVID-19 pandemic. International Journal of Mental Health and Addiction. https://doi.org/10.1007/s11469-020-00281-5

Hayes, B., Burgell, R., Apputhurai, P., Garg, M., \& Knowles, S. R. (in press). Extending the common sense model to explore the impact of visceral sensitivity on quality of life in an inflammatory bowel disease cohort. Turkish Journal of Gastroenterology.

Hayes, B., Moller, S., Wilding, H., Burgell, R., Apputhurai, P., \& Knowles, S. R. (2020). Application of the common sense model in inflammatory bowel disease: A systematic review. Journal of Psychosomatic Research. https://doi.org/10.1016/j.jpsychores. 2020.110283

Hu, L., \& Bentler, P. M. (1999). Cutoff criteria for fit indexes in covariance structure analysis: Conventional criteria versus new alternatives. Structural Equation Modeling: A Multidisciplinary Journal, 6(1), 1-55. https://doi.org/10.1080/10705519909540118 
Kiebles, J. L., Doerfler, B., \& Keefer, L. (2010). Preliminary evidence supporting a framework of psychological adjustment to inflammatory bowel disease. Inflammatory Bowel Diseases, 16(10), 1685-1695. https://doi.org/10.1002/ibd.21215

Knipe, D., Evans, H., Marchant, A., Gunnell, D., \& John, A. (2020). Mapping population mental health concerns related to COVID19 and the consequences of physical distancing: A Google trends analysis. Wellcome Open Research. https://doi.org/10. 12688/wellcomeopenres.15870.2

Knowles, S. R., Cook, S. I., \& Tribbick, D. (2013). Relationship between health status, illness perceptions, coping strategies and psychological morbidity: A preliminary study with IBD stoma patients. Journal of Crohn's \& Colitis, 7(10), e471-478. https:// doi.org/10.1016/j.crohns.2013.02.022

Knowles, S. R., Graff, L. A., Wilding, H., Hewitt, C., Keefer, L., \& Mikocka-Walus, A. (2018). Quality of life in inflammatory bowel disease: A systematic review and meta-analyses-part I. Inflammatory Bowel Diseases, 24(4), 742-751. https://doi.org/ 10.1093/ibd/izx 100

Knowles, S. R., Wilson, J. L., Connell, W. R., \& Kamm, M. A. (2011). Preliminary examination of the relations between disease activity, illness perceptions, coping strategies, and psychological morbidity in Crohn's disease guided by the common sense model of illness. Inflammatory Bowel Diseases, 17(12), 2551-2557. https://doi.org/10.1002/ibd.21650

Leventhal, H., Meyer, D., \& Nerenz, D. (Eds.). (1980). The common sense representation of illness danger (Vol. 2). Elsevier Science \& Technology.

Lin, C. Y., Broström, A., Griffiths, M. D., \& Pakpour, A. H. (2020). Investigating mediated effects of fear of COVID-19 and COVID-19 misunderstanding in the association between problematic social media use, psychological distress, and insomnia. Internet Interventions, 21, 100345. https://doi.org/10.1016/j. invent.2020.100345

Lovibond, S. H., \& Lovibond, P. F. (1995). Manual for the depression anxiety stress scales (2nd ed.). Psychology Foundation of Australia.

McCombie, A. M., Mulder, R. T., \& Gearry, R. B. (2013). How IBD patients cope with IBD: A systematic review. Journal of Crohn's \& Colitis, 7(2), 89-106. https://doi.org/10.1016/j. crohns.2012.05.021

McCombie, A. M., Mulder, R. T., \& Gearry, R. B. (2015). Coping strategies and psychological outcomes of patients with inflammatory bowel disease in the first 6 months after diagnosis. Inflammatory Bowel Diseases, 21(10), 2272-2280. https://doi. org/10.1097/MIB.0000000000000476

Mertens, G., Gerritsen, L., Duijndam, S., Salemink, E., \& Engelhard, I. M. (2020). Fear of the coronavirus (COVID-19): Predictors in an online study conducted in March 2020. Journal of Anxiety Disorders, 74, 102258. https://doi.org/10.1016/j.janxdis.2020. 102258

Mikocka-Walus, A., Knowles, S. R., Keefer, L., \& Graff, L. (2016). Controversies revisited: A systematic review of the comorbidity of depression and anxiety with inflammatory bowel diseases. Inflammatory Bowel Diseases, 22(3), 752-762. https://doi.org/ 10.1097/MIB.0000000000000620

Mosli, M., Alourfi, M., Alamoudi, A., Hashim, A., Saadah, O., Al Sulais, E., et al. (2020). A cross-sectional survey on the psychological impact of the COVID-19 pandemic on inflammatory bowel disease patients in Saudi Arabia. Saudi Journal of Gastroenterology: Official Journal of the Saudi Gastroenterology Association, 26(5), 263. https://doi.org/10.4103/sjg.SJG_220_ 20

Mukhtar, S. (2020). Psychological health during the coronavirus disease 2019 pandemic outbreak. International Journal of Social
Psychiatry, 66(5), 512-516. https://doi.org/10.1177/00207 64020925835

Perz, C. A., Lang, B. A., \& Harrington, R. (2020). Validation of the fear of COVID-19 scale in a US college sample. International Journal of Mental Health and Addiction. https://doi.org/10. 1007/s11469-020-00356-3

Rahman, M. A., Hoque, N., Alif, S. M., Salehin, M., Islam, S. M. S., Banik, B., et al. (2020). Factors associated with psychological distress, fear and coping strategies during the COVID-19 pandemic in Australia. Globalization and Health, 16(1), 1-15. https://doi.org/10.1186/s12992-020-00624-w

Satici, B., Gocet-Tekin, E., Deniz, M. E., \& Satici, S. A. (2020). Adaptation of the Fear of COVID-19 Scale: Its association with psychological distress and life satisfaction in Turkey. International Journal of Mental Health and Addiction. https://doi.org/ 10.1007/s11469-020-00294-0

Schmidt, S., Mühlan, H., \& Power, M. J. (2006). The EUROHISQoL 8-item index: Psychometric results of a cross-cultural field study. The European Journal of Public Health, 16(4), 420-428. https://doi.org/10.1093/eurpub/cki155

Sehgal, P., Ungaro, R. C., Foltz, C., Iacoviello, B., Dubinsky, M. C., $\&$ Keefer, L. (2020). High levels of psychological resilience associated with less disease activity, better quality of life, and fewer surgeries in inflammatory bowel disease. Inflammatory Bowel Diseases. https://doi.org/10.1093/ibd/izaa196

Sexton, K. A., Walker, J. R., Graff, L. A., Bernstein, M. T., Beatie, B., Miller, N., et al. (2017). Evidence of bidirectional associations between perceived stress and symptom activity: A prospective longitudinal investigation in inflammatory bowel disease. Inflammatory Bowel Diseases, 23(3), 473-483. https:// doi.org/10.1097/MIB.0000000000001040

Svedlund, J., Sjödin, I., \& Dotevall, G. (1988). GSRS—A clinical rating scale for gastrointestinal symptoms in patients with irritable bowel syndrome and peptic ulcer disease. Digestive Diseases and Sciences, 33(2), 129-134. https://doi.org/10.1007/ BF01535722

Trindade, I. A., \& Ferreira, N. B. (2020). COVID-19 Pandemic's effects on disease and psychological outcomes of people with inflammatory bowel disease in Portugal: A preliminary research. Inflammatory Bowel Diseases. https://doi.org/10.1093/ ibd/izaa261

van der Have, M., Brakenhoff, L. K., van Erp, S. J., Kaptein, A. A., Leenders, M., Scharloo, M., et al. (2015). Back/joint pain, illness perceptions and coping are important predictors of quality of life and work productivity in patients with inflammatory bowel disease: A 12-month longitudinal study. Journal of Crohn's \& Colitis, 9(3), 276-283. https://doi.org/10.1093/ ecco-jcc/jju025

van der Have, M., Minderhoud, I. M., Kaptein, A. A., Leenders, M., Siersema, P. D., Fidder, H. H., \& Oldenburg, B. (2013). Substantial impact of illness perceptions on quality of life in patients with Crohn's disease. Journal of Crohn's \& Colitis, 7(8), e292-e301. https://doi.org/10.1016/j.crohns.2012.11.002

van Erp, S. J., Brakenhoff, L. K., Vollmann, M., van der Heijde, D., Veenendaal, R. A., Fidder, H. H., et al. (2017). Illness perceptions and outcomes in patients with inflammatory bowel disease: Is coping a mediator? International Journal of Behavioral Medicine, 24(2), 205-214. https://doi.org/10.1007/ s12529-016-9599-y

Worldometer. (2021). COVID-19 Coronavirus Pandemic. Retrieved 15 March, 2021, from https://www.worldometers.info/coron avirus/

Zhang, M., Hong, L., Zhang, T., Lin, Y., Zheng, S., Zhou, X., et al. (2016). Illness perceptions and stress: Mediators between disease severity and psychological well-being and quality of life 
among patients with Crohn's disease. Patient Preference and Adherence, 10, 2387-2396. https://doi.org/10.2147/PPA.S1184 13

Zingone, F., Siniscalchi, M., Savarino, E. V., Barberio, B., Cingolani, L., D'Incà, R., et al. (2020). Perception of the COVID-19 pandemic among patients with inflammatory bowel disease in the time of telemedicine: Cross-sectional questionnaire study.
Journal of Medical Internet Research, 22(11), e19574. https:// doi.org/10.2196/19574

Publisher's Note Springer Nature remains neutral with regard to jurisdictional claims in published maps and institutional affiliations.

\section{Authors and Affiliations}

\section{Bree Hayes ${ }^{1} \cdot$ Pragalathan Apputhurai $^{2} \cdot$ Antonina Mikocka-Walus $^{3} \cdot$ Manuel Barreiro-de Acosta $^{4}$. Charles N. Bernstein ${ }^{5} \cdot$ Rebecca Burgell $^{6}$. Johan Burisch ${ }^{7}$. Floor Bennebroek Evertsz ${ }^{8} \cdot$ Nuno Ferreira $^{9}$. Lesley A. Graff ${ }^{5}$. Inês A. Trindade ${ }^{10,11}$. Richard Gearry ${ }^{12} \cdot$ Bobby Lo $^{7}$. Anna Mokrowiecka ${ }^{13}$. Gabriele Moser ${ }^{14}$. Megan Petrik ${ }^{15} \cdot$ Andreas Stengel $^{16,17}$. Simon R. Knowles ${ }^{1,6,18,19,20,21}$ (B)}

1 Department of Psychological Sciences, School of Health Sciences, Swinburne University of Technology, PO Box 218, Hawthorn, VIC 3122, Australia

2 Department of Health Science and Biostatistics, School of Health Sciences, Swinburne University of Technology, Hawthorn, VIC, Australia

3 School of Psychology, Deakin University, Burwood, Melbourne, VIC, Australia

4 IBD Unit, University Hospital Santiago de Compostela, Santiago, Spain

5 University of Manitoba and IBD Clinical and Research Centre, Max Rady College of Medicine, Winnipeg, MB, Canada

6 Department of Gastroenterology, Alfred Health and Monash University, Prahran, VIC, Australia

7 Gastrounit, Medical Division, Hvidovre University Hospital, Hvidovre, Denmark

8 Amsterdam University Medical Centers, Amsterdam, The Netherlands

9 Department of Social Sciences, University of Nicosia, Nicosia, Cyprus

10 University of Coimbra, Coimbra, Portugal

11 Department of Molecular and Clinical Medicine, Institute of Medicine, Sahlgrenska Academy, University of Gothenburg, Gothenburg, Sweden
12 Department of Medicine, University of Otago, Christchurch, New Zealand

13 Department of Digestive Tract Diseases, Medical University of Lodz, Lodz, Poland

14 Medical University of Vienna, Vienna, Austria

15 University of Minnesota Medical School, Minneapolis, MN, USA

16 Department of Psychosomatic Medicine and Psychotherapy, University Hospital Tübingen, Tübingen, Germany

17 Department for Psychosomatic Medicine, Charité Center for Internal Medicine and Dermatology, Charité-Universitätsmedizin Berlin, Corporate Member of Freie Universität Berlin, Humboldt-Universität zu Berlin, and Berlin Institute of Health, Berlin, Germany

18 Department of Gastroenterology, Royal Melbourne Hospital, Parkville, VIC, Australia

19 Department of Medicine, University of Melbourne, Melbourne, VIC, Australia

20 Department of Mental Health, St Vincent's Hospital, Fitzroy, VIC, Australia

21 Department of Psychiatry, The University of Melbourne, Melbourne, VIC, Australia 